\title{
Tropical cooling and the onset of North American glaciation
}

\author{
P. Huybers ${ }^{1}$ and P. Molnar ${ }^{2}$ \\ ${ }^{1}$ Department of Earth and Planetary Sciences, Harvard University, Cambridge MA, USA \\ ${ }^{2}$ Department of Geological Sciences and Cooperative Institute for Research in Environmental Sciences, University of \\ Colorado, Boulder CO, USA
}

Received: 20 April 2007 - Published in Clim. Past Discuss.: 15 May 2007

Revised: 27 July 2007 - Accepted: 31 August 2007 - Published: 13 September 2007

\begin{abstract}
We offer a test of the idea that gradual cooling in the eastern tropical Pacific led to cooling of North America and the initiation of glaciation $\sim 3 \mathrm{Myr}$ ago. Using modern climate data we estimate how warming of the eastern tropical Pacific affects North American temperature and ice-ablation. Assuming that the modern relationship holds over the past millions of years, a $\sim 4^{\circ} \mathrm{C}$ warmer eastern tropical Pacific between 3-5 Ma would increase ablation in northern North America by approximately two meters per year. By comparison, a similar estimate of the ablation response to variations in Earth's obliquity gives less than half the magnitude of the tropically-induced change. Considering that variations in Earth's obliquity appear sufficient to initiate glaciations between $\sim 1-3 \mathrm{Ma}$, we infer that the warmer eastern equatorial Pacific prior to $3 \mathrm{Ma}$ suffices to preclude glaciation.
\end{abstract}

\section{Introduction}

Milankovitch (1941) hypothesized that when the Northern Hemisphere is relatively distant and less pointed toward the sun during summer, ablation is weak and Northern Hemisphere icesheets grow - and that under less favorable orbital conditions, icesheets decay. Elaborated upon in the following decades, this hypothesis nonetheless remains the predominant view regarding the control of glaciation (e.g. Imbrie et al., 1992). Such glacial cycles are, however, the exception when considering the whole of Earth's history (e.g. Zachos, 2001). Indeed, for glacial cycles to occur over the past few million years the climate would seem to be precariously poised between glaciated and unglaciated states, particularly if icesheets are to wax and wane in response to the relatively weak redistribution of insolation induced by orbital variations - no more than some tens of $\mathrm{W} / \mathrm{m}^{2}$ and usually

Correspondence to: P. Huybers

(phuybers@fas.harvard.edu) much less. Milankovitch's hypothesis suggests that glaciation would be precluded if summer ablation were greater by an amount equivalent to that associated with orbital variations. Here we consider whether warmer tropical sea-surface temperature can account for the apparent absence of glacial cycles in North America prior to 3Ma.

There is a growing interest in whether the tropical climate could change high-latitude conditions (e.g. Cane, 1998). In particular, a change in tropical SSTs may be capable of altering climates at high latitudes through atmospheric teleconnections (Cane and Molnar, 2001; Philander and Fedorov, 2003; Molnar and Cane, 2002). Recent estimates of eastern Pacific SSTs using $\delta^{18} \mathrm{O}$ (e.g. Ravelo et al., 2004; Haywood et al., 2005), $\mathrm{Mg} / \mathrm{Ca}$ (e.g. Wara et al., 2005; Ravelo et al., 2006), and alkenones (e.g. Lawrence et al., 2006) show that temperatures were $\sim 4^{\circ} \mathrm{C}$ warmer between $\sim 3$ to $5 \mathrm{Ma}$ than is typical today (but see Rickaby and Halloran (2005) for a different view), and $\delta^{18} \mathrm{O}$ and $\mathrm{Mg} / \mathrm{Ca}$ measurements indicate that western tropical Pacific SSTs were cooler by $\sim 1^{\circ} \mathrm{C}$ (Wara et al., 2005; Ravelo et al., 2006). The implied flattening of the tropical Pacific zonal SST gradient between $\sim 3$ to $5 \mathrm{Ma}$ is thus similar to, if more complete than, the SST relaxation during typical modern El Niño events. (Modern El Niño events involve a seasonal warming in the eastern Equatorial Pacific of only $\sim 2^{\circ} \mathrm{C}$.) Thus, the idea has emerged that tropical Pacific SSTs resembled a permanent El Niño state during much of the Pliocene, with a warm SST extending across the Pacific, and with extratropical climates mimicking those associated with El Niño teleconnections (e.g. Federov et al., 2006; Molnar and Cane, 2002; Philander and Fedorov, 2003). The warming of much of Canada and Alaska during El Niño events suggests that a warm eastern equatorial Pacific Ocean may explain the absence of continental ice sheets in the period preceding $\sim 3 \mathrm{Ma}$ (e.g. Barreiro et al., 2006).

Haywood et al. (2007) challenged this scenario of tropical inhibition of glaciation. They explored the sensitivity

Published by Copernicus Publications on behalf of the European Geosciences Union. 
(a)

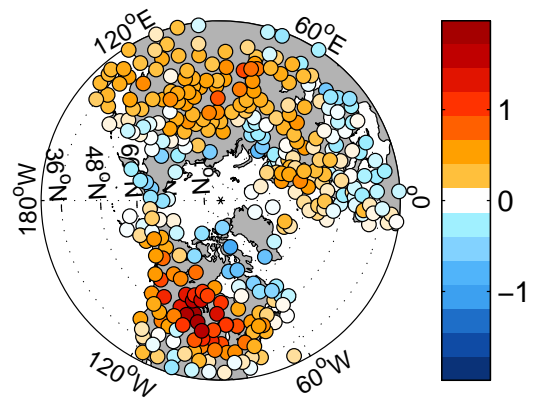

(c)

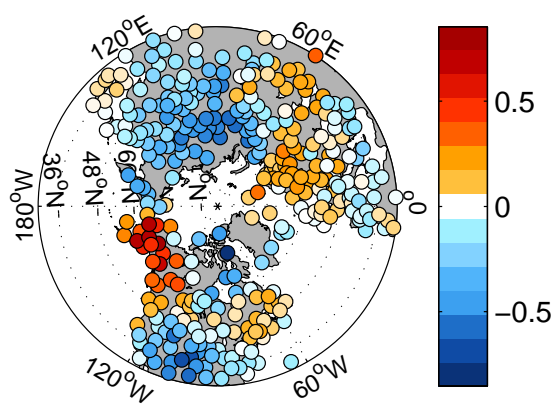

(b)

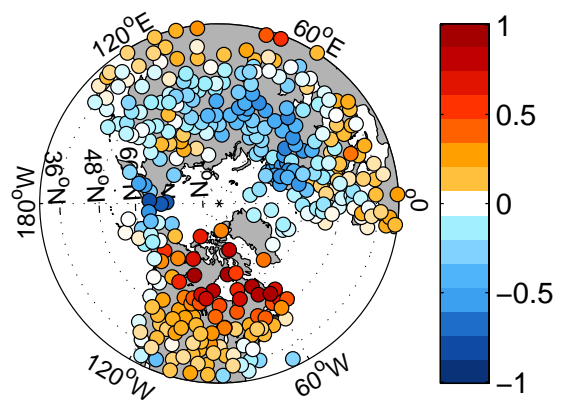

(d)

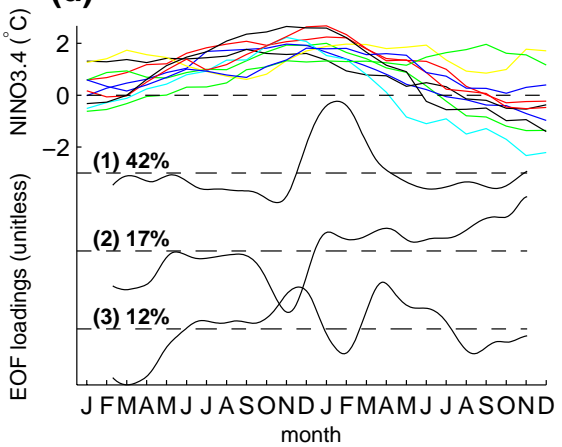

Fig. 1. Singular value decomposition of surface air temperature variability during El Niño events for regions North of $30^{\circ} \mathrm{N}$. (a-c) The spatial patterns (empirical orthogonal functions) associated with modes one through three. Shading indicates the temperature change in degrees Celsius from a one-standard-deviation increase in the corresponding principal component. Note that the two leading patterns indicate a warming concentrated in the interior of northern North America. (d) (top) The NINO3.4 temperature index during a two-year interval for the ten largest El Niño events since 1880. (below) The temporal variability (principal components) associated with modes one through three. Dashed lines indicate the zero-level and percentages indicate the relative amount of variance each mode describes. Note that the second principal component has a positive loading during the second half of the El Niño interval, suggesting that an El Niño event causes northern North America to warm during the ablation season.

of a coupled GCM to changes in tropical temperatures and concluded that warming the eastern equatorial Pacific would have a small influence on North American glaciation on the basis of small changes in the global annual mean temperature. More locally, however, warming the eastern equatorial Pacific in their model appears to warm the high-latitudes of North America by as much as $5^{\circ} \mathrm{C}$ in the winter and $2^{\circ} \mathrm{C}$ in the summer (Haywood et al., 2007, Fig. 1b) - consistent with other studies (Barreiro et al., 2006). Investigation of the local North American temperature response, as well as the structure of the full seasonal cycle, seems necessary prior to drawing conclusions regarding El Niño's influence on glaciation.

As simple as a warmer eastern tropical Pacific may seem for accounting for the absence of icesheets before $\sim 3 \mathrm{Ma}$, it needs to be reconciled with a fundamental component of Milankovitch's hypothesis - that summer ablation must increase. El Niño teleconnections are clearly documented to cause winter warming in North America (e.g. Ropelewski and Halpert, 1986; Trenberth et al., 1998), but to increase ablation of ice, summer - not winter - must warm. This conundrum motivates us to explore the influence of El Niño on the full seasonal cycle of temperature in North America and then to extrapolate this relationship to past climates.

While our focus is on eastern tropical Pacific temperatures, other components of the climate could also contribute to, or themselves explain, the absence of glaciation in North America during the early Pliocene. Such components include higher concentrations of greenhouse gases (e.g. Haywood et al., 2005), greater ocean transport of heat (e.g. Rind and Chandler, 1991), or decreased precipitation in response to a less stratified North Pacific (Haug et al., 2005) . But the strong evidence that the eastern tropical Pacific was warmer during the early Pleistocene prompts our consideration of whether this warming and the associated climatic teleconnections could alone account for the absence of North American glaciation. The calculation is in the spirit of what might be done on the back of envelope - with the aim of estimating whether eastern equatorial Pacific cooling could lower summer ablation sufficiently to permit initiation of glaciation. 


\section{High-latitude temperature responses to El Niño}

We begin by making an empirical estimate of the highlatitude temperature response to El Niño events using empirical data. The analysis relies mostly upon the Global Historical Climatology Network (GHCN) (Peterson and Vose, 1997), which provides daily resolution instrumental temperature. As the GHCN records give only daily maximum and minimum temperature, we use the average of these two to estimate daily average temperature. The GHCN network has recently been updated through 2006, and most records extend back to at least 1950 and some as far back as 1850 . Note, in particular, that El Niño events are associated with small variations in precipitation and snow accumulation at high-latitudes, so that discussion is focused on temperature. The extra-tropical temperature response is analyzed in three steps:

Identification: The strength of El Niño is estimated by averaging the sea-surface-temperature anomalies (Kaplan et al., 1998) over the NINO3.4 region, between $120^{\circ} \mathrm{W}$ and $170^{\circ} \mathrm{W}$ and within $5^{\circ}$ of the equator, yielding a NINO3.4 index. After smoothing the NINO3.4 index with a five-month running mean, we selected the ten largest temperature excursions. These largest temperature excursions demarcate "El Niño intervals", defined to begin in January of 1877, 1888, 1902, 1905, 1940, 1972, 1982, 1986, 1991, and 1997 and to extend for two years, thus encapsulating the period of anomalous eastern equatorial Pacific SSTs. (If instead of ten events, five or fifteen are selected, the results do not change.)

Extra-tropical response: We average as many of the ten El Niño intervals as are present in each GHCN temperature record into a single, composite El Niño interval. Averaging helps to suppress random temperature variability and thus isolate the consistent extra-tropical response to an El Niño event. (Later, we return to these averages, as well the standard deviation between El Niño intervals, when discussing ablation.) Only records from the northern extra-tropics that span at least one El Niño event are included, giving 363 records with, on average, 62 years of daily observations.

Time/space description: A singular value decomposition (e.g. von Storch and Zwiers, 1999) of the 363 composite El Niño intervals yields the spatial and temporal patterns which "explain" the greatest possible variance of extratropical temperatures. Our primary interest is in the lowfrequency temperature response to warming in the eastern equatorial Pacific. Thus, we first smooth each composite temperature record using a 90 day tapered running average to suppress synoptic scale variations while still retaining the seasonal temperature variability. We also truncate the first and last 45 days of the record (i.e. half the length of the smoothing window) so that the retained points are equally smoothed. The first three principal component / empirical orthogonal function pairs (PC/EOF) are readily interpreted (see Fig. 1). The leading PC/EOF pair, accounting for $42 \%$ of the temperature variance, indicates warming between December

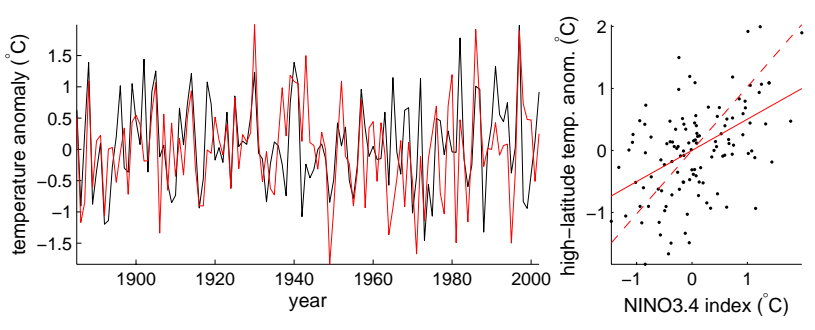

Fig. 2. (Left) Tropical Pacific (black) and high-latitude continental (red) temperature anomalies. Tropical temperature anomalies from the NINO3.4 region are averaged between June to May and highlatitude temperature anomalies from continental stations between $160^{\circ} \mathrm{W}$ and $55^{\circ} \mathrm{W}$ and North of $50^{\circ} \mathrm{N}$ are averaged between December to November. Both time-series are plotted against the year associated with December. (Right) The cross-correlation between the NINO3.4 index and high-latitude temperature anomalies is 0.5 . A least-squares fit of the linear trend (solid line) yields a slope of 0.5 , and a bias-corrected estimate of the slope yields 1 (dashed line).

and March, and is concentrated in the interior of North America at mid-latitudes. Note that at mid-latitudes winter temperature can breach the freezing point and can be associated with modest changes in ablation.

The second PC/EOF pair, which explains $17 \%$ of the temperature variance, indicates warmer temperatures throughout northern North America during the second year of the El Niño interval. This sustained high-latitude warming of North America appears the most pertinent with regard to glaciation. We checked this relationship further by comparing the NINO3.4 index with northern North American surface air temperatures from the Climate Research Unit's monthly resolved temperature compilation (Jones and Moberg, 2003). (To be specific, we define the region between $130^{\circ} \mathrm{W}$ and $70^{\circ} \mathrm{W}$ and north of $50^{\circ} \mathrm{N}$ as the high-latitudes or northern North America.) These data reach back to 1885 , earlier than most GHCN records. For the NINO3.4 index we took the annual average for the period from June to May (the warmest El Niño months), and for the surface air temperatures we used the average between January and December (consistent with the warm phase of the second PC).

After detrending both time-series, the cross-correlation between the surface air temperature and NINO3.4 between 1885 and 2005 is 0.5 (Fig. 2). Monte Carlo experiments, accounting for the autocorrelation in both time-series, indicate this correlation is significant at the $99 \%$ confidence level. A least-squares estimate of the slope treating the NINO3.4 index as the independent variable and high-latitude temperatures as the dependent variable yields 0.5 , but this is biased low owing to noise in the NINO3.4 index. A simple correction is to divide the slope by the cross-correlation (see Sokal and Rohlf, 1981; Frost and Thompson, 2000), giving a bias corrected slope of 1 , but this assumes that the two quantities covary perfectly, and is biased high. The slope estimates of 1 and $1 / 2$ are thus indicative of upper and lower bounds. 
(a)

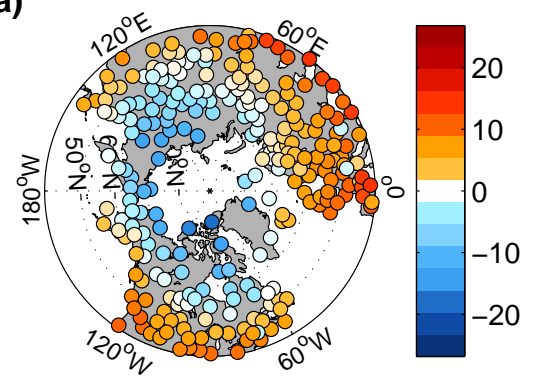

(c)

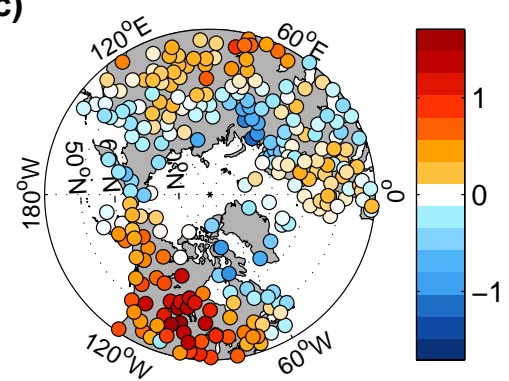

(b)

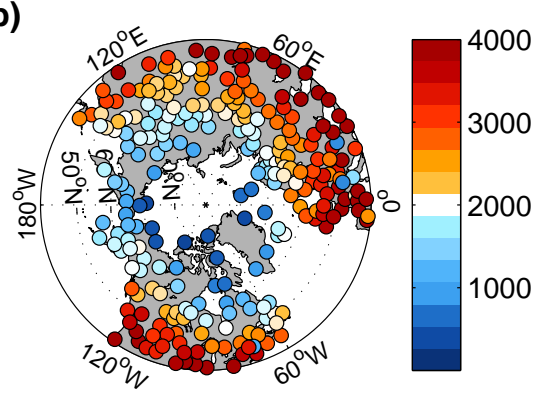

(d)

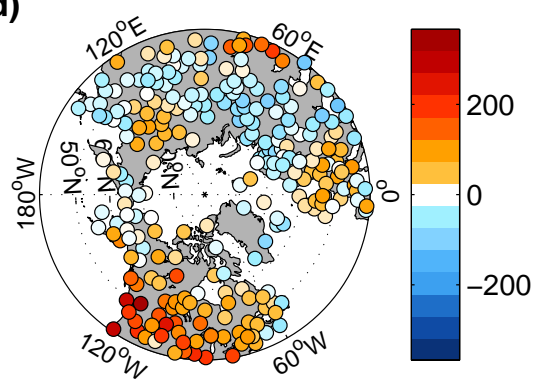

Fig. 3. (a) Mean annual temperature in ${ }^{\circ} \mathrm{C}$ for regions North of $40^{\circ} \mathrm{N}$ from the GHCN database (Peterson and Vose, 1997), (b) the number of positive-degree-days in ${ }^{\circ} \mathrm{C}$-days, and $(\mathbf{c}, \mathbf{d})$ their respective anomalies during El Niño events. Temperature and PDD anomalies are the December to November average of the ten largest El Niños intervals since 1880, or fewer, if the record begins after 1880.

(Reassuringly, the conclusions we later come to hold within a factor-of-two range in the sensitivity of northern North America to tropical temperatures.)

The third PC/EOF, which accounts for $12 \%$ of the variance, is the final useful descriptor of temperature variability - subsequent PC/EOF pairs explain less than $6 \%$ of the variance. The third PC/EOF most closely resembles the timeevolution of the NINO3.4 temperature during an El Niño event - excepting the January to February negative excursion. Measures of teleconnections with El Niño that rely upon a linear fit with NINO3.4 tend to emphasize this mode, giving the incorrect impression that El Niño warming in North America is confined to the margins (see e.g. Halpert and Ropelewski, 1992). In actuality, PC/EOF pairs one and two show not only that warming is greatest in the interior of North America, but also that some warming occurs during the spring, summer, and fall - suggesting that the eastern tropical Pacific could influence glaciation. A similar analysis performed using only North American temperature records yields these same conclusions.

\section{Temperature and ablation}

Surface temperature reconstructions in the eastern Equatorial Pacific indicate a long-term cooling trend of approximately four degrees Celsius since four million years ago (e.g. Ravelo et al., 2004; Wara et al., 2005; Lawrence et al., 2006).
The simplest approach to estimating the extra-tropical response is to assume that in the past the eastern equatorial Pacific was uniformly warmer throughout the year, and that the annual average warming observed for NINO3.4 is proportional to a constant temperature change in the extra-tropical Northern Hemisphere. We estimate the proportionality as the ratio of the annual average (December to November) land temperature anomaly to the annual average (June to May) NINO3.4 temperature during the ten largest El Niño events. The NINO3.4 (Fig. 1) and northern North American temperature anomalies (Fig. 3c) both average $\sim 1^{\circ} \mathrm{C}$, giving a ratio of $\sim 1$, as might be expected from EOFs one and two (Fig. 1) and from the bias-corrected regression between the NINO3.4 index and average temperature in northern North America (Fig. 2).

Is it reasonable to extrapolate El Niño's influence on highlatitude temperature to the case of a constantly warmer eastern Equatorial Pacific? Two recent general circulation model simulations permit comparison: (1.) Barreiro et al. (2006) impose an approximately four degree Celsius annual average warming on the eastern Equatorial Pacific as well as warming in the Indian and Atlantic oceans and obtain approximately four degrees of annual average warming in the interior of northern North America, thus simulating a temperature response in close agreement with our extrapolation both in terms of spatial distribution and magnitude (see our Fig. 3c and their Fig. 8) and (2.) Haywood et al. (2007) impose an 
approximately two degree warming in the eastern equatorial Pacific on a background climate that is already made warmer than the present, and they obtain a northern North American warming of about two degrees in the winter and half a degree in the summer, thus yielding an annual average magnitude roughly half that of our extrapolation, but referenced to a different background climate state. We conclude that our temperature extrapolation is consistent with model simulations to within a factor of two.

High-latitude temperature anomalies, of themselves, do not indicate changes in ablation simply because warmer temperatures that are still sub-freezing do not much affect ablation. To quantify the influence of daily temperature on ablation we use positive degree days (PDDs),

$\mathrm{PDD}=\sum \delta_{d} T_{d}$

$T_{d}$ is the daily temperature and $\delta_{d}$ is zero if $T_{d}<0^{\circ} \mathrm{C}$ and one otherwise. The composite El Niño intervals, however, come from averages over different years, and the distribution of temperature around this average needs to be accounted for (see Braithwaite, 1984). For example, if the average temperature on January first hovers just below freezing, the expected PDDs are nonetheless positive because some realizations of January first temperature will inevitably exceed freezing. We assume a normal distribution with a standard deviation calculated from, for example, all January first temperatures in a record. The expected number of PDDs becomes,

$$
<\mathrm{PDD}>=\sum_{d=1}^{365} \int_{0}^{\infty} x \gamma\left(\bar{T}_{d}, \sigma_{d}, x\right) d x .
$$

$\gamma$ is a normal distribution of temperature with mean $\bar{T}$ and standard deviation $\sigma$ on day $d$, and $x$ is temperature in Celsius integrated from the freezing point upward. All PDDs reported in this paper are the expected values, but with the brackets left off for simplicity. For stations where seasonal temperatures hover near freezing, PDDs calculated using Eq. (2) exceed those using Eq. (1) by as much as $50 \%$.

PDDs tend to be smallest at high-latitudes and in the interior of continents. A one degree annual average rise in the NINO3.4 index - corresponding to a moderate El Niño event - is associated with, on average, a $90^{\circ} \mathrm{C}$-day increase in northern North America (Fig. 3d). Note that peak differences in PDDs lie south of peak differences in temperature because more days breach the freezing point to the south. PDDs increase super-linearly with temperature because both the magnitude increases and the number of days with positive temperatures increases. Thus, assuming that extra-tropical temperatures continue to scale linearly with the NINO3.4 index, a $2{ }^{\circ} \mathrm{C}$ warming in the NINO3.4 region is associated with a $300^{\circ} \mathrm{C}$-day increase; a $4^{\circ} \mathrm{C}$ tropical warming gives a $630^{\circ} \mathrm{C}$-day increase, but this pushes the limits of plausibility in extrapolating teleconnections from large modern El Niño events to climates that include a warmer eastern equatorial
Pacific. In Eurasia, during El Niño events, PDDs decrease slightly in the interior and increase slightly near the margins.

Common scaling factors relating ablation rates (in terms of water equivalent thickness) to PDDs range from $3 \mathrm{~mm} /\left(\right.$ day $\left.^{\circ} \mathrm{C}\right)$ for snow-covered surfaces to $8 \mathrm{~mm} /\left(\right.$ day $\left.^{\circ} \mathrm{C}\right)$ for bare ice (Braithwaite and Zhang, 2000; LeFrebre et al., 2002). The higher rate of ice ablation owes to a lower albedo. Thus a $300\left(\right.$ day $\left.^{\circ} \mathrm{C}\right)$ increase in northern North America corresponds to an ablation rate higher by one to two meters per year than today. Considering that for the modern climate northern North America receives an average of $0.4 \mathrm{~m}$ of precipitation per year (according to GHCN records, Peterson and Vose, 1997), such a large increase in ablation would presumably inhibit glaciation.

So far we have assumed that the response to eastern tropical Pacific warming is constant through the seasons, as a simplest possible case, but a seasonally varying response is perhaps more realistic. Furthermore, paleoceanographic observations of past temperatures are usually spaced at centuries or longer, and therefore cannot resolve ENSO variability over shorter durations, let alone 3-7 years, if such variability is present at all. Thus we cannot distinguish whether the long-term decline in eastern equatorial temperatures owes to a shift in mean temperature or to decreases in the frequency or amplitude of El Niño events (e.g. Haywood et al., 2007). To explore the implications of seasonal temperature variability - as opposed to a constant response across the seasons we perturbed each extra-tropical temperature record by a seasonally varying temperature anomaly. Specifically, we add to the temperature on each day of a record the temperature anomaly on the corresponding day in the composite El Niño interval, taken between December to November. The resulting increase in PDDs is actually somewhat larger for northern North America than that obtained from the annual average scaling described earlier. Thus, the inference of greater ablation in response to a warmer eastern equatorial Pacific holds assuming either the seasonally varying temperature perturbation associated with modern El Niño events or a constant annual warming.

In contrast to our line of reasoning, Kukla et al. (2002) suggest that El Niño conditions will increase the moisture supply to North America and, thus, actually promote glaciation. Using the same procedure of averaging temperature for the ten largest El Niño intervals but now for precipitation, we find that precipitation increases in North America by no more than $10 \mathrm{~cm} /$ year between $25^{\circ}$ to $50^{\circ} \mathrm{N}$, and that at higher latitudes precipitation increases by less than $1 \mathrm{~cm} /$ year. These observational results appear consistent with the simulation of Barreiro et al. (2006, their Fig. 7). While changes in precipitation almost certainly contribute to changes in the mass balance of North American icesheets, we estimate El Niño increases the magnitude of ablation by more than a factor of ten relative to changes in precipitation. Thus, as is generally the case for glaciers and icesheets (e.g. Paterson, 1994), we anticipate ablation to exert the primary control on glaciation. 
(a)

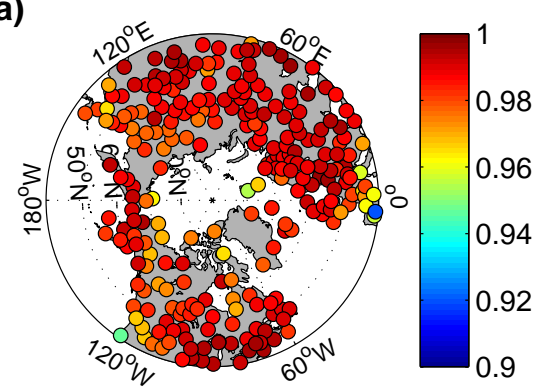

(c)

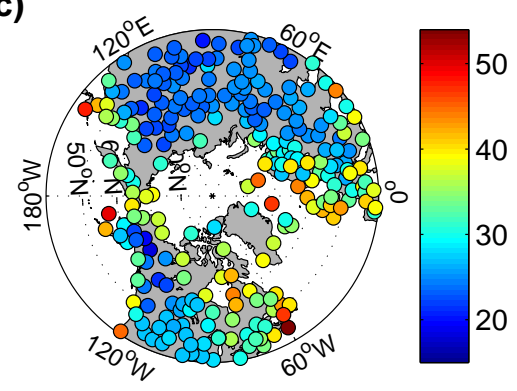

(b)

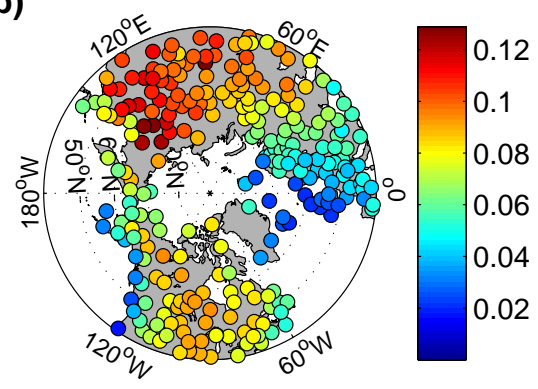

(d)

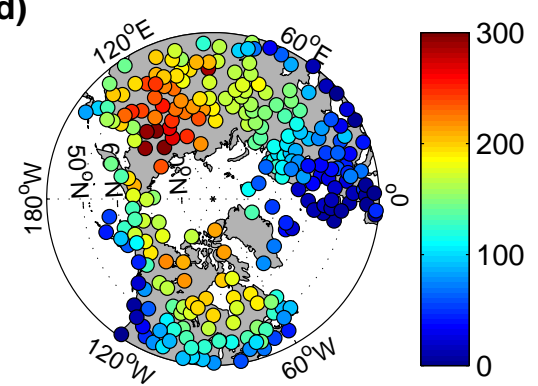

Fig. 4. The temperature and positive degree day (PDD) response to changes in insolation at latitude North of $40^{\circ}$ N. (a) The squared-crosscorrelation between lagged insolation and the average seasonal cycle in temperature. (b) The sensitivity of temperature to insolation, in units of ${ }^{\circ} \mathrm{C} /\left(\mathrm{W} / \mathrm{m}^{2}\right)$. (c) The number of days temperature lags incoming insolation at the top of the atmosphere. (d) The calculated difference in PDDs resulting from changing the tilt of Earth's spin axis, or its obliquity, from $22.2^{\circ}$ to $24.2^{\circ}$, an amount similar to the amplitude of an average obliquity cycle.

\section{Comparison with insolation}

The magnitude of the tropically-induced changes in PDDs can be placed in context by comparison with the effects of Earth's orbital variations. If changes in Earth's orbital configuration, and the resulting shifts in insolation, force North America between unglaciated and glaciated states, then the difference in ablation between orbital configurations associated with glacial and interglacial periods indicates the forcing required to preclude glaciation. Two factors complicate simple application of this logic. First, glacial cycles might occur independent of orbital variation and are perhaps only paced by changes in insolation (e.g. Tziperman et al., 2006). Such self-sustained oscillation seem most relevant for the $\sim 100$ kyr late Pleistocene glacial cycles, but the early Pleistocene $40 \mathrm{kyr}$ glacial cycles appear to respond directly to radiative forcing, with the timing and amplitude of changes in glaciation closely following the insolation integrated over the summertime (Huybers, 2006). As the integrated summer energy is almost wholly a function of obliquity, we use the difference in PDDs between low and high obliquity to gauge the forcing required to preclude glaciation.

The second complication is that feedbacks - for example, involving ice-albedo, icesheet instabilities, greenhouse gases, or ocean and atmospheric circulation shifts - could amplify the glacial response to insolation variability. Furthermore, Liu and Herbert (2004) found that eastern tropical Pacific temperatures covary with obliquity and the extent of glaciation, confounding separation of orbital and tropical $\mathrm{Pa}$ cific influences on glaciation. Insofar as climate feedbacks contribute only after ice is growing, however, their effects are irrelevant with respect to the onset of glaciation.

Earth's orbital variations are well-known over the last $5 \mathrm{Ma}$ (e.g. Berger and Loutre, 1992), and these have been specified within a general circulation model (Jackson and Broccoli, 2003) and, more simply, energy balance models (e.g. Huybers and Tziperman, 2007) to determine the sensitivity of PDDs. Our experiments with energy balance models, however, indicate that the relationship between solar insolation and temperature can be winnowed down to three parameters - a lag, $L$; sensitivity, $S$; and constant, $B$ - and we opt for a very simple representation,

$T_{i}(d+L)=S_{i} I\left(d, \phi_{i}\right)+B_{i}$,

In words, the lagged daily average temperature, $T(d+L)$, at station $i$ is related to daily average insolation, $I(d, \phi)$, by a sensitivity, $S$, and a constant temperature, $B . \phi_{i}$ is the latitude at which temperature is recorded. The average crosscorrelation obtained between Eq. (3) and the average seasonal cycle at each site is 0.99 (Fig. 4a) - as high as could be 

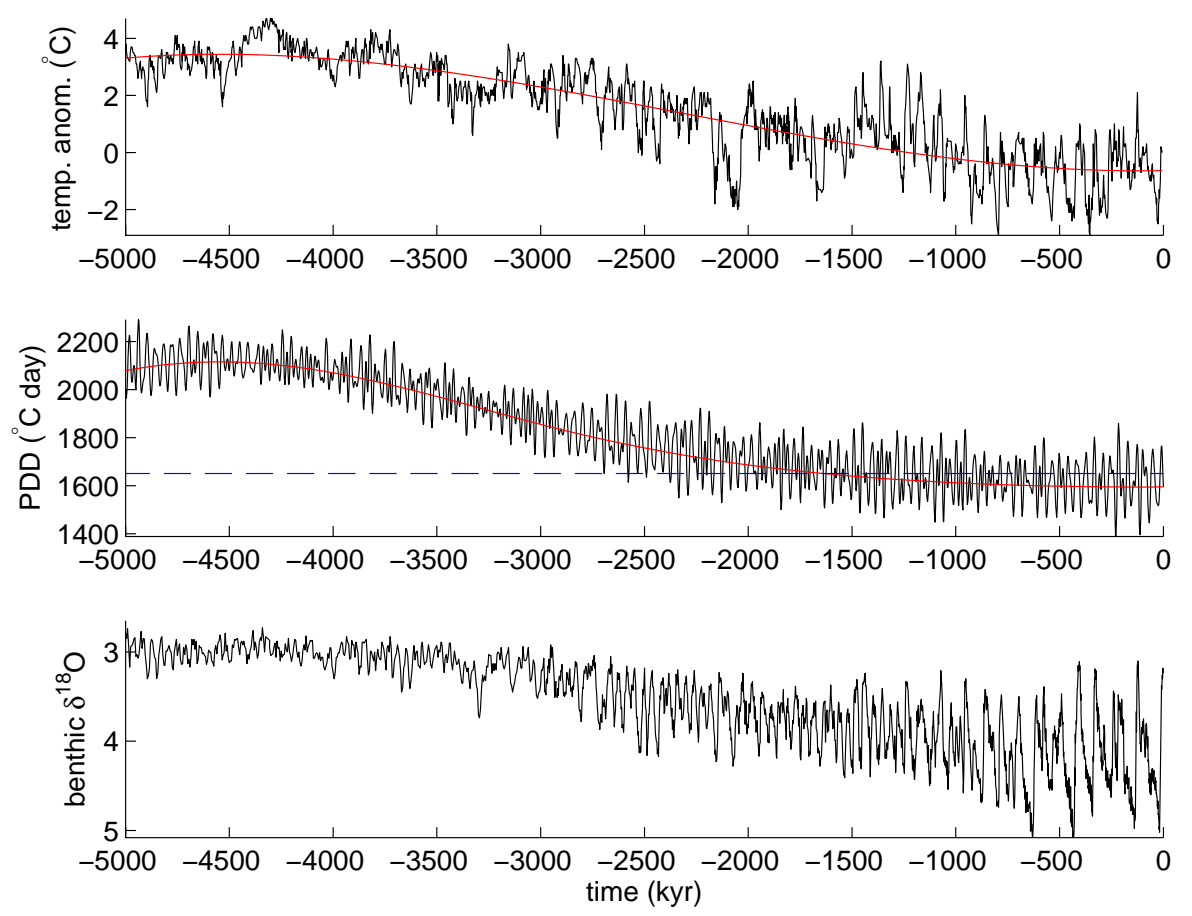

Fig. 5. Glacial implications of tropical cooling. (top) Alkenone derived SST anomalies for the eastern equatorial Pacific (from Lawrence et al., 2006), normalized so that the most recent estimate is $0^{\circ} \mathrm{C}$. Red line indicates the long-term trend, fit using a third-order polynomial. (middle) Calculated average positive degree days for northern North America (between $70^{\circ} \mathrm{W}$ and $130^{\circ} \mathrm{W}$ and above $50^{\circ} \mathrm{N}$ ) obtained by applying temperature perturbations expected to result from tropical anomalies (red line) and also including orbital variations (black line). For reference, the lowest number of PDDs obtained by $2.7 \mathrm{Ma}$ is indicated (dashed line). (bottom) A combination of many benthic $\delta^{18} \mathrm{O}$ records (Lisiecki and Raymo, 2005), where more positive values indicate greater ice-volume. Note the y-axis is reversed.

obtained through fitting an energy-balance-model. Eastern continental interiors show the greatest sensitivity and least lag with insolation, presumably because these regions are the most isolated from the buffering effects of the oceans.

We expect the relationship between temperature and insolation estimated using modern observations to hold under different orbital configurations, at least to first order, because the variations in insolation are small relative to the mean and are concentrated at the seasonal cycle. For example, shifting obliquity from $22.2^{\circ}$ to $24.2^{\circ}$ causes an increase in the amplitude (measured from maximum to minimum intensity) of the annual cycle at $65^{\circ} \mathrm{N}$ of $40 \mathrm{~W} / \mathrm{m}^{2}$ but only a $6 \mathrm{~W} / \mathrm{m}^{2}$ change in the annual mean insolation. In the case of precession, shifting perihelion from winter to summer solstice causes an increase in the amplitude of the annual cycle by $54 \mathrm{~W} / \mathrm{m}^{2}$ and the annual mean insolation is invariant.

Assuming that the relationship between temperature and insolation (Eq. 3) estimated from modern data holds under different configurations of Earth's orbit, we calculate the temperature at these sites for the seasonal cycles when obliquity is $22.2^{\circ}$ and $24.2^{\circ}$. PDDs are calculated from temperature using Eq. (2). The specified two-degree increase in obliquity is a typical amplitude for an obliquity cycle and, according to our calculations, causes an average increase of $170^{\circ} \mathrm{C}$-days in northern North America. Jackson and Broc- coli (2003) obtain a similar result from their GCM calculation. The amount by which PDDs change in response to changes in obliquity depends on the local change in insolation and the sensitivity of temperature to changes in insolation. Thus the PDD response to an increase in obliquity is largest in continental interiors, away from the buffering effects of the ocean, and at high latitudes where obliquityinduced difference in insolation are greatest.

Finally, we consider the combined influence of tropical temperature and orbital variations. As our interest is in discerning if the long-term eastern tropical Pacific temperature changes could have initiated glaciation, we fit a third order polynomial to the $5 \mathrm{Myr}$ temperature record of Lawrence et al. (2006). This fit indicates an overall cooling of $4^{\circ} \mathrm{C}$, and we use this as a proxy for the decrease in the NINO3.4 index. The anomalies in the NINO3.4 proxy are used to calculate extra-tropical temperature changes, as described in Sect. 3. The orbitally-forced temperature changes over the last $5 \mathrm{Ma}$ are calculated as described in Sect. 4, in this case including changes in obliquity, precession, and eccentricity (Berger and Loutre, 1992). Figure 5 shows the variations in PDDs from the combined tropical- and insolation-forced temperature response, assuming that the modern standard deviations in temperature also hold for the past.

The inferred decrease in PDDs during the past $5 \mathrm{Myr}$ is 
$\sim 600^{\circ} \mathrm{C}$-days, much larger than the $\sim 170^{\circ} \mathrm{C}$-days associated with variations in obliquity (Fig. 5). The steepest tropically induced change in PDDs occurs between $3.5 \mathrm{Ma}$ and $2.5 \mathrm{Ma}$, coinciding with a rapid increase in the $\delta^{18} \mathrm{O}$ of benthic foraminifera, and which Mudelsee and Raymo (2005) associated with the onset of Northern Hemisphere glaciation. Although the modern estimate of the ratio between tropical and high-latitude warming need not hold under much warmer tropical conditions, the tropical forcing appears sufficiently strong that even were its influence decreased by a factor of two, it would still be larger than the obliquity-induced changes in PDDs.

\section{Conclusions}

According to Milankovitch's hypothesis, summer ablation must dip below a threshold value for glaciation to initiate. Our calculations indicate that the decline in eastern tropical Pacific temperatures since $\sim 5 \mathrm{Ma}$ would decrease ablation in northern North America by more than twice as much as orbitally-induced changes, and thus could readily bring the climate close enough to glaciation such that, during a favorable orbital configuration, an icesheet would form. We thus conclude that tropical cooling appears sufficient to switch North America from an unglaciated state to one with intermittent glaciations. Understanding the puzzle of what caused the eastern equatorial Pacific to cool off on a timescale too long to invoke the atmosphere-ocean-cryosphere system by itself now appears all the more pressing.

Acknowledgements. We thank J. C. H. Chiang and G. Roe for helpful discussion as well as M. Cane, F. Peeters, C. Wunsch, and an anonymous reviewer for useful comments on earlier drafts of this manuscript.

Edited by: F. Peeters

\section{References}

Barreiro, M., Philander, G., Pacanowski, R., and Fedorov, A.: Simulations of warm tropical conditions with application to middle Pliocene atmospheres, Clim. Dyn., 26, 349-365, 2006.

Berger, A. and Loutre, M. F.: Astronomical solutions for paleoclimate studies over the last 3 million years, Earth Planet. Sci. Lett., 111, 369-382, 1992.

Braithwaite, R.: Calculation of degree-days for glacier-climate research, Zeitschrift fur Gletscherkunde und Glazialgeologie, 20, $1-8,1984$

Braithwaite, R. and Zhang, Y.: Sensitivity of mass balance of five Swiss glaciers to temperature changes assessed by tuning a degree-day model, J. Glaciology, 152, 7-14, 2000.

Cane, M.: A role for the tropical Pacific, Science, 282, 59-60, 1998.

Cane, M. and Molnar, P.: Closing of the Indonesian seaway as a precursor to east African aridification around 3-4 million years ago, Nature, 411, 157-162, 2001.
Fedorov, A., Dekens, P., McCarthy, M., Ravelo, A., deMenocal, P., Barreiro, M., Pacanowski, R., and Philander, S.: The Pliocene Paradox (Mechanisms for a Permanent El Niño), Science, 312, 1485-1489, 2006.

Frost, C. and Thompson, S.: Correcting for regression dilution bias: comparison of methods for a single predictor variable, Journal of the Royal Statistical Society, 163, 173-190, 2000.

Halpert, M. and Ropelewski, C.: Surface temperature patterns associated with the Southern Oscillation, J. Climate, 5, 577-593, 1992.

Haug, G., Ganopolski, A., Sigman, D., Rosell-Mele, A., Swann, G., Tiedemann, R., Jaccard, S., Bollmann, J., Maslin, M., Leng, M., and Eglinton, G.: North Pacific seasonality and the glaciation of North America 2.7 million years ago, Nature, 433, 821-825, 2005.

Haywood, A., Dekens, P., Ravelo, A., and Williams, M.: Warmer tropics during the mid-Pliocene? Evidence from alkenone paleothermometry and a fully coupled oceanatmosphere GCM, Geochem. Geophys. Geosyst., 6, Q03010, doi:10.1029/2004GC000799, 2005.

Haywood, A., Valdes, P., and Peck, V.: A permanent El Niñolike state during the Pliocene?, Paleoceanography, 22, PA1213, doi:10.1029/2006PA001323, 2007.

Huybers, P.: Early Pleistocene glacial cycles and the integrated summer insolation forcing, Science, 313, 508-511, 2006.

Huybers, P. and Tziperman, E.: Integrated summer insolation forcing and 40000 year glacial cycles: the perspective from an icesheet/energy-balance model, Paleoceanography, in press.

Imbrie, J., Boyle, E. A., Clemens, S. C., Duffy, A., Howard, W. R., Kukla, G., Kutzbach, J., Martinson, D. G., McIntyre, A., Mix, A. C., Molfino, B., Morley, J. J., Peterson, L. C., Pisias, N. G., Prell, W. L., Raymo, M. E., Shackleton, N. J., and Toggweiler, J. R.: On the structure and origin of major glaciation cycles. 1. Linear Responses to Milankovitch Forcing, Paleoceanography, 7, 701-738, 1992.

Jackson, C. and Broccoli, A.: Orbital forcing of Arctic climate: mechanisms of climate response and implications for continental glaciation, Clim. Dyn., 21, 539-557, doi:10.1007/ s00382-003-0351-3, 2003.

Jones, P. and Moberg, A.: Hemispheric and large-scale surface air temperature variations: An extensive revision and an update to 2001, J. Climate, 16, 206-223, 2003.

Kaplan, A., Cane, M., Kushnir, Y., Clement, Y., Blumenthal, M., and Rajagopalan, B.: Analyses of global sea surface temperature 1856-1991, J. Geophys. Res., 103, 18 567-18 589, 1998.

Kukla, G., Clement, A., Cane, M. Gavin, J., and Zebiak, S.: Last interglacial and early glacial ENSO, Quat. Res., 58, 27-31, doi: 10.1029/2002PA000837, 2002.

Lawrence, K., Liu, Z., and Herbert, T.: Evolution of the Eastern Tropical Pacific Through Plio-Pleistocene Glaciation, Science, 312, 79-83, 2006.

Lefebre, F., Gallee, H., Van Ypersele, J., and Huybrechts, P.: Modeling of large-scale melt parameters with a regional climate model in South-Greenland during the 1991 melt season, Ann. Glaciol., 35, 391-397, 2002.

Liu, Z. and Herbert, T.: High latitude signature in Eastern Equatorial Pacific Climate during the Early Pleistocene Epoch, Nature, 427, 720-723, 2004.

Lisiecki, L. and Raymo, M.: A Pliocene-Pleistocene stack of 57 
globally distributed benthic $\delta^{18} \mathrm{O}$ records, Paleoceanography, 20, PA1003, doi:10.1020/2004PA001071, 2005.

Milankovitch, M.: Kanon der Erdbestrahlung und seine Andwendung auf das Eiszeitenproblem, Royal Serbian Academy, Belgrade, 1941.

Molnar, P. and Cane, M.: El Niño's tropical climate and teleconnections as a blueprint for pre-Ice Age climates, Paleoceanography, 17(2), 1021, doi:10.1029/2001PA000663, 2002.

Mudelsee, M. and Raymo, M.: Slow dynamics of the Northern Hemisphere glaciation, Paleoceanography, 20, PA4022, doi:10.1029/2005PA001153, 2005.

Paterson. W. Physics of Glaciers. Pergamon Press, 3rd edition, 1994.

Peterson, T. and Vose, R.: An overview of the Global Historical Climatology Network temperature database, Bull. Am. Meteorol. Soc., 78, 2837-2849, 1997.

Philander, G. and Fedorov, A.: Role of tropics in changing the response to Milankovitch forcing some three million years ago, $\mathrm{Pa}$ leoceanography, 1045, doi:10.1029/2002PA000837, 2003.

Ravelo, A., Andreasen, D., Lyle, M., Lyle, A., and Wara, M.: Regional climate shifts caused by gradual global cooling in the Pliocene epoch, Nature, 429, 263-267, 2004.

Ravelo, A., Dekens, P., and McCarthy, M.: Evidence for El Niñolike conditions during the Pliocene, GSA Today, 16(3), 4-11, 2006.
Rickaby, R. and Halloran, P.: Cool La Niña during the warmth of the Pliocene?, Science, 307, 1948-1952, 2005.

Rind, D. and Chandler, M.: Increased ocean heat transports and warmer climate, J. Geophys. Res., 96, 7437-7461, 1991.

Ropelewski, C. and Halpert, M.: North American precipitation and temperature patterns associated with the El Niño/Southern Oscillation, Monthly Weather Review, 114, 2352-2362, 1986.

Storch, v. H. and Zwiers, F.: Statistical analysis in climate research, Cambridge University Press, 1999.

Sokal, R. and Rohlf, F. Biometry, 2nd edition, Freeman, 1981.

Trenberth, K., Branstator, G., Karoly, D., Kumar, A., Lau, N., and Ropelewski, C.: Progress during TOGA in understanding and modeling global teleconnections associated with tropical sea surface temperatures, J. Geophys. Res., 103, 14 291-14 324, 1998.

Tziperman, E., Raymo, M., Huybers, P., and Wunsch, C.: Consequences of pacing the Pleistocene $100 \mathrm{kyr}$ ice ages by nonlinear phase locking to Milankovitch forcing, Paleoceanography, 21, PA4206, doi:doi:10.1029/2005PA001241, 2006.

Wara, M., Ravelo, C., and Delaney, M.: Permanent El Niño-like conditions during the Pliocene warm period, Science, 309, 758761, 2005.

Zachos, J., Pagani, M., Sloan, L., Thomas, E., and Billups, K.: Trends, Rhythms, and Aberrations in Global Climate 65 Ma to Present, Science, 292, 686-693, 2001. 